\title{
The costs of early hearing screening in England and Wales
}

\author{
J C Stevens, D M B Hall, A Davis, C M Davies, S Dixon
}

Department of Medical Physics and Clinical Engineering, Royal Hallamshire Hospital, Sheffield S10 2JF

J C Stevens

C M Davies

\section{Department of Community Paediatrics, University of Sheffield \\ D M B Hall}

MRC Institute of Hearing Research, University of Nottingham A Davis

SCHARR (Sheffield Centre for Health and Related Research), University of Sheffield S Dixon

Correspondence to: Dr Stevens.

Accepted 8 July 1997

\begin{abstract}
A survey was carried out in 10 centres in England and Wales to determine the costs of hearing screening in the first year of life. The screens that were studied were targeted neonatal, universal neonatal, and the health visitor distraction test (HVDT) or alternative surveillance. Valid data were available from five centres for targeted neonatal screening (TNS), three for universal neonatal screening (UNS), and nine for the HVDT, although only five of the HVDT screens had valid data for follow up costs.

The neonatal costs were consistent across the centres surveyed, whereas those for the HVDT screen varied considerably.

The mean service costs for TNS, UNS, and the HVDT at 1994 prices were $£ 5052$, $£ 13881$, and $£ 24519$ for a standardised district of 1000 live births.

Three conclusions seem justified. Firstly, UNS need not be prohibitively expensive as it costs considerably less than HVDT screening. Secondly, TNS appears to be a relatively inexpensive way of improving the age of identification of a proportion of the congenitally hearing impaired. Thirdly, given the published yields for UNS and the HVDT, the results indicate that UNS offers the most cost effective overall approach with alternative systems in place to identify late onset permanent hearing losses.

(Arch Dis Child 1998;78:14-19)
\end{abstract}

Keywords: hearing screening; neonatal screening; health technology asssessment; health visitor distraction test

Congenital sensorineural hearing loss should ideally be identified in the first three months of life. Certainly, by the age of 1 , all children with this problem should be identified, but there is still no consensus as to the most cost effective way of achieving this goal. In the UK, the health visitor distraction test (HVDT), done at around 7 months of age, is used in almost every district as a method of universal hearing screening. ${ }^{1}$ It cannot be used, however, in the first three months of life, and many districts have reported a disappointing yield with poor coverage, sensitivity, and specificity. ${ }^{2-4} \mathrm{~A}$ few districts have abandoned the HVDT and substituted it with a parent questionnaire. ${ }^{5}$

Neonatal screening has been technically possible for at least 15 years. Three methods are now available: measurement of behavioural responses, for example the portable auditory response cradle ${ }^{6-8}$; the detection of transient evoked otoacoustic emissions ${ }^{9-15}$; and the auditory brainstem response. ${ }^{16} 17$

Recently, recommendations for "targeted" (testing those considered to be at risk) neonatal hearing screening (TNS) in the $\mathrm{UK},{ }^{18}$ and universal neonatal screening (UNS) in the US, ${ }^{19}$ have been put forward with the aim of reducing the age at which hearing loss is detected and hearing aids are fitted.

Over 80 centres in the UK now carry out a targeted screen on babies known to be at high risk of hearing loss. ${ }^{1}$ Two centres are known to undertake UNS as a routine service and another centre was doing so as part of a research project during the period of this survey, although the project has now stopped running.

Deciding on the optimum approach to hearing screening is complex, and each of the many possible screening programmes has strengths and weaknesses. As well as the more obvious factors such as sensitivity and specificity of the available test procedures, it is necessary to consider factors such as coverage and psychological aspects. When there is no overwhelming argument for one particular policy, cost becomes an important consideration. ${ }^{20}$ In this paper, we describe the actual costs of programmes for screening congenital sensorineural hearing loss in the first year of life. The more complex issues of costs and benefits will not be addressed here, but will be the subject of a further report.

Few data have been published on the costs of hearing screening. ${ }^{21}{ }^{22}$ Results of a survey by Davis et al, of which this parallel survey forms a part, show that most districts that provide neonatal or health visitor based screening did not have data on the costs of the service. ${ }^{1}$ Those that did have information may not have been representative.

\section{Methods}

Nine audiological centres in England and Wales were identified on the basis of these criteria: (1) currently providing a neonatal screening service; (2) providing a postneonatal screen in the first year of life, either by the HVDT or a surveillance method such as a questionnaire; (3) ablility to provide statistical data on their service performance; (4) ablility to identify staff costs; and (5) known to have research or audit interests in hearing screening. One additional centre was identified as having useful data on postneonatal screening, but it had no neonatal screen. The lead audiologist in each of the 10 centres was approached and all agreed to participate. A list of centres is given in the acknowledgments. 
Four of the centres are teaching centres. Three are in London and so have increased costs due to London weighting in the salaries. The sizes of the populations served cover the range found in the UK, although there is a bias towards heavily populated urban areas rather than rural areas.

A questionnaire was devised and mailed to each centre in September 1995. The responder was asked to gather the required information, and the questionnaire was then completed jointly by the responder and one of the first two authors by a telephone interview.

The questionnaire set out to gather data on the nature of the screens, the screening methods used, the staffing levels for the primary screen, and any retest or follow up procedures. Also included were questions on coverage, pass levels, referral rates, and the methods used to maintain a quality service (for example, cover for holidays, provision for equipment breakdowns, speed of follow up, and intervention for screen positive children). Appendix 1 gives the key points of the questionnaire which yielded data from a sufficient number of centres to be useful and the codes used for the results tables.

It was not possible in many centres to separate the costs of the neonatal screen and the follow up work that resulted from it. The costs shown for the neonatal screening programmes therefore include the screen and the follow up work.

It was possible to estimate directly the staff time involved as the work was usually done by a small number of staff with time allocated for this work. For those centres where the neonatal screen follow up was carried out at a different location, specific staff were not always allocated to the work involved, and in these cases staff time was estimated from the number of tests required.

For the postneonatal screen, large numbers of staff were involved and the respondent was therefore asked to give the number of children seen per session, the type and grade of staff, the number of sessions devoted to the service each week, and the proportion of children tested at home.

The postneonatal screen follow up was the most difficult to cost as, although records were available for the number of screen failures, the number of retests at the secondary level was usually unknown and estimates had to be made based on a limited number of audit sources. In addition, data on follow up to the ear, nose, and throat and/or tertiary services also had to be largely estimated, although this was not a large proportion of the total cost of the follow up.

The proportion of total working time that professional staff could devote to direct patient contact was estimated from a range of local and national sources. The range, as a proportion of a 44 week working year, varied from $70-85 \%$ dependent on the type of staff.

\section{Analysis}

Respondents who were initially unable to provide precise figures for any items were asked to obtain the data if possible; otherwise, an estimate was used if the respondent was able to justify it. Missing data were handled in this way: (1) if they amounted to only a minor part of the total cost, values were inserted based on the most reliable figures from other centres; and (2) if the missing data were likely to constitute a substantial part of the total costs, figures for that part of the centre's service, that is, neonatal, postneonatal, or postneonatal follow up, were omitted from the analysis.

The total staff costs for each part of the service were then calculated from the total staff time by using appropriate salary scales as of 1 April 1994, including London weighting when necessary, and $12 \%$ employer's costs. Finally $40 \%$ was added to the salary totals to cover overheads such as central staff costs, equipment depreciation, consumables, accommodation, heating, lighting, travel, etc. The choice of a pro rata figure is based on data which show that salary costs make up around $65-75 \%$ of total NHS expenditure. ${ }^{23}$ The costs of parents' time and travel expenses were not included.

The use of a fixed figure of $40 \%$ rather than a detailed analysis of overheads was justified on the grounds that differences in overhead costs would be relatively small compared with differences in direct costs among centres and those among the three different types of screen considered.

The annual costs were then standardised for each centre to derive costs for each part of the service for a hypothetical centre serving an area with 1000 live births per annum.

\section{Results}

Tables 1, 2, and 3 show a summary of the results from the questionnaire and the final figures calculated for the costs. Overall a good quality of service was claimed, with adequate provision made for staff sickness, holidays, and for equipment failure. Follow up protocols and timings varied widely from centre to centre.

Data were obtained from all of the 10 centres that were invited to participate. For the neonatal screen, data were not available for one centre, and were incomplete in another where the centre was in the first year of providing a service. For the postneonatal screen and follow up, data were obtained from nine centres. For four of these, however, the follow up data were incomplete. Sufficient data were therefore available to calculate costs for neonatal screening in eight centres, for the postneonatal screen in nine centres, and for the postneonatal screen follow up in five centres.

The staff involved in the neonatal screening varied considerably among centres with no common pattern. They included nurses, clinical scientists, medical technical officers, assistant technical officers, clinical medical officers, and non-professional staff, with the diagnostic work being done by the higher graded specialised staff.

Figure 1 summarises the final calculated figures for the cost of neonatal hearing screening in each centre, standardised to the cost of running the service per 1000 live births. TNS will detect fewer cases of hearing impairment than UNS, so a complete comparison of the costs 
Table 1 Neonatal screen and follow up

\begin{tabular}{|c|c|c|c|c|c|c|}
\hline Centre & $\begin{array}{l}\text { NS1 type of } \\
\text { screen: } \\
\text { targeted }(T) / \\
\text { universal }(U)\end{array}$ & $\begin{array}{l}\text { NS2: screening method: } A B R \text {, } \\
\text { TEOAE, PARC }+\end{array}$ & $\begin{array}{l}\text { NS3: } \\
\text { number of } \\
\text { live births } \\
\text { each year }\end{array}$ & $\begin{array}{l}\text { NS4: number } \\
\text { targeted each } \\
\text { year }(\%)\end{array}$ & $\begin{array}{l}\text { NS5 and NS6: \% } \\
\text { completing screen }\end{array}$ & $\begin{array}{l}\text { Total cost of screen } \\
\text { and follow up per } \\
1000 \text { births }(£)\end{array}$ \\
\hline A & $\mathrm{T}$ & $\mathrm{ABR}$, diagnostic $\mathrm{ABR}$ for follow up & 6955 & $471(6.8)$ & 97.8 & 5954 \\
\hline B & $\mathrm{T}$ & $\begin{array}{l}\text { TEOAE and ABR (if fail either } \\
\text { ear) }\end{array}$ & $6000^{\star}$ & $516(8.6)$ & 95.5 & 4981 \\
\hline D & $\mathrm{T}$ & $\begin{array}{l}\text { ABR, TEOAE (partial } \\
\text { coverage-research) }\end{array}$ & 8335 & $674(8.1)$ & 93 & 5318 \\
\hline $\mathrm{E}$ & $\mathrm{U}$ & $\begin{array}{l}\text { TEOAE, TEOAE follow up, then } \\
\text { diagnostic ABR, TEOAE in one } \\
\text { ear = pass unless parent wishes } \\
\text { for retest }\end{array}$ & 3695 & 3695 & 91.5 & 13119 \\
\hline $\mathrm{F}$ & $\mathrm{T}$ & $\begin{array}{l}\text { TEOAE (twice) for inpatients and } \\
\text { outpatients, diagnostic ABR for } \\
\text { follow up }\end{array}$ & 5650 & $234(4.1)$ & 92 & 4753 \\
\hline G & $\mathrm{U}$ & $\begin{array}{l}\text { PARC (twice) (bilateral } \\
\text { stimulation), immediate follow } \\
\text { up by ABR }\end{array}$ & $3500^{\star}$ & No data & 99 (estimate) & 13747 \\
\hline $\mathrm{H}$ & $\mathrm{T}$ & $\mathrm{ABR}$ & $3000^{\star}$ & $528(17.6)$ & 94.8 & 4256 \\
\hline I & $\mathrm{U}$ & $\begin{array}{l}\text { TEOAE, ABR on unilateral and } \\
\text { bilateral failures }\end{array}$ & 4631 & 4631 & 89 & 14778 \\
\hline
\end{tabular}

$\star$ Rounded figures given.

$+\mathrm{ABR}=$ auditory brainstem response TEOAE $=$ transient evoked otoacoustic emmisions; PARC $=$ portable auditory response cradle.

Table 2 Postneonatal screen (HVDT or surveillance)

\begin{tabular}{|c|c|c|c|c|c|c|c|}
\hline Centre & $\begin{array}{l}\text { PS2: test method and pass } \\
\text { level }\end{array}$ & $\begin{array}{l}\text { PS4: } \\
\text { number } \\
\text { to be } \\
\text { tested }\end{array}$ & $\begin{array}{l}\text { PS9: number } \\
\text { actually seen in } \\
\text { one clinical } \\
\text { session }\end{array}$ & $\begin{array}{l}\text { PS9: number } \\
\text { seen in one } \\
\text { session at } \\
\text { home }\end{array}$ & $\begin{array}{l}\text { PS10: } \\
\text { proportion } \\
\text { seen at home } \\
(\%)\end{array}$ & $\begin{array}{l}\text { PS11: number of } \\
\text { staff and grade } \\
\text { (HV = health } \\
\text { visitor) }\end{array}$ & $\begin{array}{l}\text { Total cost of } \\
\text { screen per } 1000 \\
\text { population }(£)\end{array}$ \\
\hline A & Distraction test $35 \mathrm{dBA}$ & 6955 & 8 & 5 & 20 & $2 \mathrm{HV}$ & 25481 \\
\hline B & Surveillance & $6000^{\star}$ & 8 & 4 & & $1 \mathrm{HV}$ & 14029 \\
\hline C & Distraction test $35-40 \mathrm{dBA}$ & 5520 & $8.5 \ddagger$ & 4 & 25 & $1 \mathrm{HV}+$ assistant & 18123 \\
\hline $\mathrm{D}$ & Distraction test $35 \mathrm{dBA} \dagger$ & 8335 & $10 \ddagger$ & $4 \ddagger$ & $<10$ & $2 \mathrm{HV}$ & 18610 \\
\hline $\mathrm{E}$ & Distraction test $35 \mathrm{dBA}$ & 3695 & 9.6 & & Very few & $1 \mathrm{HV}+$ assistant & 16643 \\
\hline $\mathrm{F}$ & Distraction test 35 dBA & $5500^{\star}$ & 9 & & 2 & $2 \mathrm{HV}$ & 21997 \\
\hline G & Distraction test $35-40 \mathrm{dBA}$ & $3500^{\star}$ & $8 \ddagger$ & & 1 & $1 \mathrm{HV}+$ assistant & 19292 \\
\hline $\mathrm{H}$ & $\begin{array}{l}\text { Surveillance questionnaire } \\
\text { at } 0,3 \text {, and } 8 \text { months }\end{array}$ & $3000^{\star}$ & 6 & & No data & $1 \mathrm{HV}$ & 17678 \\
\hline $\mathrm{J}$ & Distraction test & 2600 & 10 & $5-6$ & 14 & $2 \mathrm{HV}$ & 26579 \\
\hline
\end{tabular}

* Rounded figures given.

† Considering changing to $45 \mathrm{dBA}$ and the use of an assistant.

\# Figures required some degree of estimation of such factors as non-attendance rates.

PS1-All centres aimed for universal postneonatal screening, centres A and F reported additional active screening of those considered at risk. Only dominant method is shown for test method.

PS5, PS6, PS7. The actual coverage in the seven centres where data were available, varied between 84 and $94 \%$ except for one centre which reported coverage of only $69 \%$. A target figure for coverage was only reported by four centres, two giving $90 \%$ and two giving $95 \%$.

needs to take into account the sensitivity and yield of each screen.

In general, the staff used in the postneonatal screen were health visitors. In seven cases, a second person was used: a heath visitor in four centres and an assistant in three centres.

The staff involved in the follow up of the postneonatal screen varied considerably, with most work being done by clinical medical officers, clinical scientists, and medical technical officers with administrative and clerical support.

Table 3 Postneonatal screen follow up

\begin{tabular}{|c|c|c|c|c|}
\hline Centre & $\begin{array}{l}\text { PF1: annual number } \\
\text { of referrals (as \% of } \\
\text { live births) }\end{array}$ & $\begin{array}{l}\text { PF2: number of } \\
\text { additional } \\
\text { appointments for } \\
\text { follow up (as \% of live } \\
\text { births) }\end{array}$ & $\begin{array}{l}\text { PF3: number tested } \\
\text { in one session }\end{array}$ & $\begin{array}{l}\text { Total cost per } 1000 \\
\text { target population each } \\
\text { year including } 40 \% \\
\text { overhead }(£)\end{array}$ \\
\hline A & 4.3 & $4.3^{\star}$ & 8 & 3136 \\
\hline B & Under audit & Under audit & & Insufficient data \\
\hline $\mathrm{C}$ & $2.1-2.4$ & 1.1 & $\begin{array}{l}4 \text { (mainly } \\
\text { domiciliary) }\end{array}$ & Insufficient data \\
\hline D & 9.4 & 8.9 & 8 & 5757 \\
\hline $\mathrm{E}$ & 8.6 & 10.3 & 6 & 5165 \\
\hline $\mathrm{F}$ & 3 & & 10 & 3867 \\
\hline G & & & 6 & Insufficient data \\
\hline $\mathrm{H}$ & & & & Insufficient data \\
\hline J & 7.3 & $7.3^{\star}$ & 7 & 5540 \\
\hline
\end{tabular}

* Figures required some degree of estimation.
The main difficulty with establishing costs at this stage was identifying which part of the secondary tier work related to screen failures rather than other reasons for referral. This is the main reason why data from only five centres (table 3) were considered acceptable for calculating the mean cost. This cost is regarded as the least accurate of the three presented in this paper. Costs of further follow up (for example, to ear, nose, and throat services) were difficult to estimate as little data were available for this part of the service. Figure 2 summarises the cost of the postneonatal screen and follow up. The mean figures for a standardised centre covering 1000 live births for each of the three screens were: TNS $£ 5052$, UNS $£ 13$ 881, and universal postneonatal (HVDT/surveillance) $£ 24519$. The breakdown of the HVDT/ surveillance figure is $£ 19826$ for the screen component and $£ 4693$ for the follow up. Figure 3 shows these figures for a typical district of 5000 live births per annum.

\section{Discussion}

The data collected for this study provide the first comparative cost analysis of neonatal and infant hearing screening in the UK. Before 


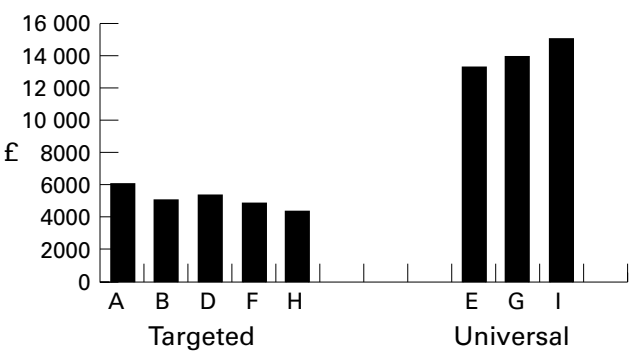

Figure 1 Total cost of neonatal screens and follow up, standardised to a district of 1000 live births.

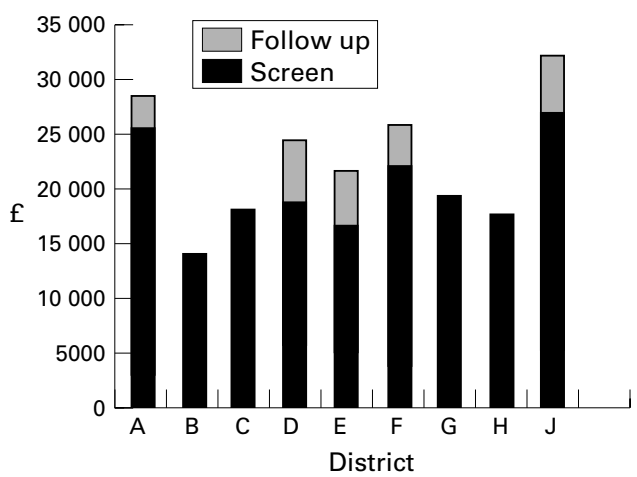

Figure 2 Costs of postneonatal screen (HVDT/surveillance) and follow up, standardised to a district of 1000 live births.

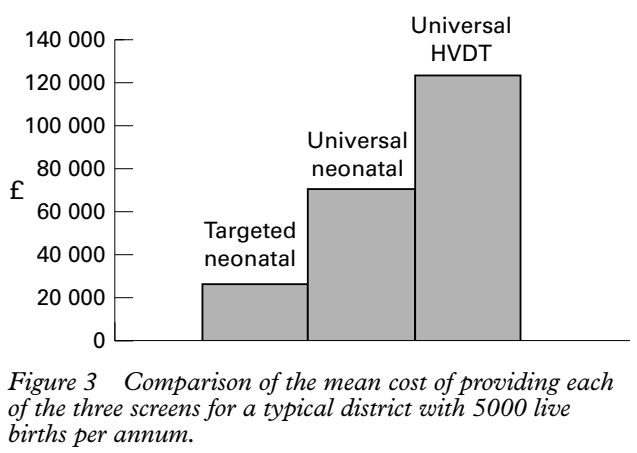

accepting these figures as a true reflection of costs, it is important to consider the weaknesses and biases of the survey.

Firstly, the centres chosen for the survey were to some extent atypical because they had accessible data of reasonable quality, an active interest in hearing screening, and were largely in urbanised areas. These characteristics could introduce a systematic bias in the costs of the service provided when compared with other centres in the UK. However, although all the participating centres had initiated a range of measures to ensure a high quality of service, these could neither be considered as unnecessary luxuries nor had they been developed purely for research purposes. Indeed, such measures are an essential part of any screening programme.

Secondly, some important data were missing. In particular, it was difficult to obtain clear information about the postneonatal follow up. Although all centres knew the screen failure rate, the numbers attending at the various follow up clinics were often uncertain because children referred through other routes were also seen at these clinics. The estimates made for the costs of postneonatal follow up are therefore somewhat less precise than for the other components of the survey. Two centres were using a surveillance method in preference to the HVDT, and the data available for referrals and follow ups resulting from this procedure were limited.

Thirdly, no attempt was made to cost the items of equipment, consumables, or other non-direct staff costs used by each service. This was justified on the basis that it was reasonable to assume that variations in capital and overheads would be small relative to the total variation in costs among centres and variation in costs among the three types of screen considered.

There are several reasons to support the validity of the costs obtained from this survey. Firstly, they agree with published cost estimates from individual centres in the UK. This is not surprising, however, as most of the relevant papers emanate from the centres which took part in this study and were probably based on similar data and estimates.

More compelling is the consistency among the figures for neonatal hearing screening for similar types of programmes among the participating centres. Although the centres differed in their approach to screening, configuration of staffing, and coverage, the results were similar. These figures are likely to be reliable because the cost calculations for TNS and UNS were largely based on the costs of a relatively small number of staff involved.

One note of caution should, however, be added for TNS. There is evidence from data within the survey that some "at risk" infants, in particular those with a family history of hearing impairment, are not being referred for screening because of practical organisational problems. An estimate can be made of the expected level of referral for the combination of risk factors: family history, $>48$ hours in neonatal intensive care unit, and craniofacial abnormality from recent studies and data within this survey. Wood et al reported a positive response of $4.5 \%$ to a question addressed to parents regarding a family history of hearing impairment. ${ }^{24}$ Combined with data from a report by Fortnum et $a l^{5}$ and data within the survey, an expected referral level of $10.5 \%$ is suggested. The median figure in table 1 is $8.1 \%$ which suggests that there is still an under referral of at risk infants in the majority of services surveyed. To correct this situation will require further resources in some centres and it may be that a moderate increase in the costs will result for TNS.

The biggest variation was in the costs of the postneonatal screen. The scatter of results is accounted for mainly by variations in staffing for the HVDT; in some centres, the test is done by two health visitors, whereas in others, a health visitor is assisted by a lower paid worker. Two centres employed one person only to do the surveillance.

One other point to consider here is the possibility of doing the HVDT with only one person using suitable equipment. This may mean that the cost can be reduced to a level close 
to that calculated for the two centres using surveillance with one health visitor only, as the time spent on each infant was not dissimilar to centres using the HVDT. The average of the costs of the screen element in these two centres was $£ 15854$, which was $£ 5106$ less than the average for the other seven centres.

There are also considerable variations in the costs of the postneonatal screen follow up. This was the most difficult part to cost as although records were available for the number of screen failures, the total number of tests at the secondary level and the number referred on to tertiary level was not accurately known.

Independent support for our figures comes from two sources. An extensive programme of UNS using transient evoked otoacoustic emissions has been done in Rhode Island, USA. ${ }^{13}$ The cost of testing each baby was estimated in 1993 at US $\$ 20$ per baby tested, ${ }^{26}$ which is equivalent to approximately $£ 13$ at 1994 prices (using general price indices and purchasing power parities). Assuming all babies are tested, the cost would be $£ 13000$ per 1000 live births. Given the differences in health care systems and costs, this is remarkably similar to the figure obtained in this survey for England and Wales.

The costs of the HVDT have been previously examined by Brown who worked in a London centre which did not take part in our survey. ${ }^{22}$ Her approach was based on a detailed analysis of referral patterns and the modelling of local data that were collected in 1986 . She estimated that the time taken for each HVDT was 23 minutes and computed the cost of each test from this figure. In our survey, an average of nine tests were done in one three and a half hour session for those centres using the distraction test (table 2). This is equivalent to 23 minutes per test, identical to Brown's figure.

For the follow up to the HVDT, she estimated that each clinic appointment for screen failures cost $£ 31$, or about $£ 60$ at 1994 prices. Our survey suggests that each screen failure needs on average two appointments, costing $£ 120$ on Brown's figures. With the range of referral rates found in our survey, this would cost between $£ 3600$ and $£ 11280$ per 1000 live births. The range of costs per 1000 live births given in table 3 was $£ 3136$ to $£ 5757$, somewhat lower than the figure estimated from Brown's data.

Another consideration, not addressed in this survey, is the set up costs for a new hearing screening service. The centres in the survey had all passed this initial phase. However, the costs of each of the three types of hearing screening considered are dominated by staff time, and the set up costs largely relate to staff training at the start of the service. Follow up services will also have a set up period, requiring skills to be gained in the management of children diagnosed earlier by neonatal screening.

In conclusion, this survey shows the costs of providing hearing screening programmes of varying kinds for neonates and infants. No attempt has been made to argue that any one model is superior.

The data provided here, however, could be used as part of an economic evaluation in

\section{Key messages}

- In England and Wales the cost of universal neonatal hearing screening was found to be considerably less than that of the HVDT done at 8 months of age

- TNS screening was found to be a relatively inexpensive way of improving the age of identification for a proportion of the congenitally hearing impaired

- From published yields, the results suggest that universal neonatal hearing screening offers the most cost effective approach to early identification of the congenitally hearing impaired

investigating the relative cost effectiveness of different strategies for early hearing screening. The main strategies to be investigated would be: (1) universal HVDT (or surveillance) only; (2) UNS only; (3) TNS with universal HVDT(or surveillance); (4) UNS with universal HVDT(or surveillance); (5)UNS with targeted HVDT(or surveillance); and (6) TNS only. We will report the results of such an analysis in due course. However, currently published data on the yields of UNS and the HVDT in the UK, summarised by Davis et al, indicate that UNS has a higher yield than the HVDT. On this basis, the results of this study indicate that UNS offers a lower cost per case identified when compared with the HVDT. With UNS in place, the yield of the HVDT is further reduced ${ }^{1}$ and the cost per case identified by the HVDT increased. ${ }^{1}$

Three tentative conclusions already seem justified, however. Firstly, UNS need not be prohibitively expensive. Its cost, taken from the survey, was considerably lower than that of the HVDT, which is current practice. Secondly, TNS appears to be relatively inexpensive and provides a low cost way of improving the age of identification for a proportion of the congenitally hearing impaired. Thirdly, given the published yields of UNS and HVDT screening, the results indicate that the most cost effective overall approach is to use UNS with alternative systems in place of the current universal HVDT for the identification of cases of late onset hearing losses.

Grateful acknowledgements are given for the help and support of these people in the production of this survey: Dr P Watkin, Dr G Sutton, Mr C Sparkes, Professor B McCormick, Dr J Bhattacharye, Dr S Fonseca, Mr R Merideth, Ms L Kimm, and Ms J
Lyons. Centres participating were: Southampton, Clwyd, Waltham Forest, Wandsworth, Sheffield, South Glamorgan, Bury, Hillingdon, Nottingham, Reading.

This work was carried out as part of a review of early detection of hearing impairment led by Professor A Davis and Professor J Bamford and funded by the Department of Health. ${ }^{1}$

1 Davis A, Bamford J M, Wilson I, et al. A critical review of the role of neonatal screening in the detection of congenita hearing impairment. Health Technol Assess 1997;(1)(10).

2 Mott A, Emond A. What is the role of the distraction test of hearing? Arch Dis Child 1994;70:10-13.

3 Robertson C, Aldridge S, Jarman F, et al. Late diagnosis of congenital sensorineural hearing impairment: why are detection methods failing? Arch Dis Child

4 Wood S, Davis A, McCormick B. Changing yield of the health visitor distraction test when targeted neonatal screening is introduced into a health district. $\mathrm{Br} \mathcal{F}$ Audiol (in press). 
5 Scanlon PE, Bamford JM. Early identification of hearing loss: screening and surveillance methods. Arch Dis Child 1990;65:479-85.

6 Bennett MJ. The auditory response cradle, a device for the objective assessment of auditory state in neonates. Symposium of the Zoological Society of London 1975;337:291-305.

7 McCormick B, Curnock DA, Spavins F. Auditory screening of special-care neonates using the auditory response cradle. Arch Dis Child 1984;59:1168-72.

8 Tucker S, Bhattacharya J. Screening of hearing impairment in the newborn using the auditory response cradle. Arch Dis Child 1992;67:911-9.

9 Johnsen NI, Bagi P, Elberling C. Evoked acoustic emissions from the human ear. III. Findings in neonates. Scand Audio 1983;12:17-24

10 Stevens JC, Webb HD, Smith MF, et al. A comparison of oto-acoustic emissions and brain stem electric response audiometry in the normal new-born and babies admitted to a special care baby unit. Clin Phys Phys Meas 1987;8:95104 .

11 Stevens JC, Webb HD, Hutchinson J, et al. Evaluation of click-evoked otoacoustic emissions in the new-born. $\operatorname{Br} \mathcal{F}$ Audiol 1991;25:11-4.

12 Kennedy CR, Kimm L, Cafarelli-Dees D, et al. Otoacoustic emissions and auditory brainstem responses in the new-born. Arch Dis Child 1991;66:1124-9.

13 White KR, Behrens TR. The Rhode Island hearing assessment project: implications for universal new-born hearing screening. Seminars in hearing. New York: Theme Medical Publishers, 1993.

14 Kemp DT, Ryan S. The use of transient evoked otoacoustic emissions in neonatal hearing screening programs. Seminars in Hearing 1993;14:30-45.

15 Watkin P. Neonatal otoacoustic emission screening and the identification of deafness. Arch Dis Child 1996;74:F16-25.
16 Galambos R, Hicks GE, Wilson MJ. The auditory brain stem response reliably predicts hearing loss in graduates of a tertiary intensive care nursery. Ear Hear 1984;5:254-60.

17 Durieux-Smith A, Picton T, Edwards C, et al. Prognostic validity of brainstem electric response audiometry in infants of a neonatal intensive care unit. Audiology 1991;30: 249-65.

18 National Deaf Children's Society (UK). Quality standards in paediatric audiology. Volume 1. Guidelines for early identification of hearing impairment. 1994.

19 National Institute of Health (USA). Early identification of hearing impairment in infants and young children. Bethesda: United States Department of Health and Human Sciences, 1993.

20 Hall DMB. Health for all children: report of the third joint working party on child health surveillance. 3rd Ed. Oxford: Oxford University Press, 1996.

21 Haggard MP. Hearing screening in children-state of the art(s). Arch Dis Child 1990;65:1193-5.

22 Brown J. Screening infants for hearing loss-an economic evaluation. 7 Epidemiol Community Health 1992:46:350-6.

23 Office of Health Economics. OHE compendium of health statistics. 9th Ed. London: OHE, 1995.

24 Wood S, Farnsworth A, Davis A, The identification and referral of babies with a family history of congenital hearing loss for neonatal screening. F Audiol Med 1995;4:25-33.

25 Fortnum H, Davis A, Butler A, et al. Health implications of changes in aetiology and referral patterns of hearing impaired children in Trent 1985-1993. Report to Trent Regional Health Authority. Nottingham: MRC Institute of Hearing Research, Nottingham University, 1996.

26 Johnson JL, Mauk GW, Takekawa MS, et al. Implementing a statewide system of services for infants and toddlers with hearing disabilities. Seminars in Hearing 1993;14:105-18.

\section{Appendix 1}

\section{Key points of questionnaire}

NEONATAL SCREEN

NS1 What kind of service is provided? (Universal screen/targeted screen/neonatal intensive care unit only/on request only)

NS2 What method is used? (transient evoked otoacoustic emissions using click stimuli, auditory brainstem response (ABR), auditory response cradle, ${ }^{8}$ combined, other)

NS3 What birth population each year is the service responsible for?

NS4 What is the number of babies targeted each year?

NS5 What is the number of babies actually screened each year?

NS6 What is the proportion of those targeted who successfully complete the screening test?

NS7 Estimate the amount of staff time which is allocated to the neonatal screen

NS8 Is a diagnostic assessment done at the same time as the screen? For example, ABR threshold. If the answer is yes, consider what proportion of the answer to NS7 should be added to the follow up costs

Follow up

NF1 What is the annual number of referrals for follow up from the neonatal screen?

NF2 How many additional appointments are made in a year for further follow up from the neonatal screen for infants in their first year of life?

NF3 How many follow up cases can be seen in the paediatric centre in a one half day session?

NF4 What clinical and support staff are employed on the relevant follow up clinic?

POSTNEONATAL FOR FIRST YEAR OF LIFE (HVDT/SURVEILLANCE) SCREEN

PS1 What kind of service is provided? (universal/universal with additional testing of at risk group/other)

PS2 and 3 What method is used?

(Distraction test at 6-8 months by health visitor only/active parental and professional education programme only/both of these/other)

PS4 What is the expected number of babies that will require testing each year?

PS5 What is the actual number of babies screened each year?

PS6 What target is set for coverage if any?

PS7 What is the proportion of those targeted who successfully complete the screening test?

PS8 Estimate the amount of staff time that is allocated to the screen

PS9 How many infants can be seen in one session of protected time both at home and in clinic?

PS10 What proportion of babies are tested in the home?

PS11 Are one or two people used for testing: (1) at home (2) in clinic

Follow up

PF1 What is the annual number of referrals for follow up from the screen?

PF2 How many additional appointments are made in a year for further follow up from the screen for infants in their first year of life?

PF3 How many follow up cases can be seen in the paediatric centre in a one half day session?

PF4 What clinical and support staff are employed on the relevant follow up clinic?

PF5 How many are referred each year to the ear, nose, and throat department?

PF6 How many are referred to a tertiary service? 